ÁLVAREZ JUNCO, José (2017). Dioses útiles. Naciones y nacionalismos. Barcelona: Ediciones Galaxia Gutenberg, 316 páginas. Miguel Ángel COSUNDINO

Avances del Cesor, V. XV, № 19, diciembre 2018, pp. 185-188.

ISSNe 2422-6580 / ISSN 1514-3899 - http://web2.rosario-conicet.gov.ar/ojs/index.php/AvancesCesor/index

\title{
ÁLVAREZ JUNCO, José (2017). Dioses útiles. Naciones y nacionalismos. Barce- lona: Ediciones Galaxia Gutenberg, 316 páginas.
}

Miguel Ángel Cosundino Facultad de Humanidades y Artes y Ciencias Sociales. Universidad Autónoma de Entre Ríos

Argentina miguelcosundino@hotmail.com

José Álvarez Junco nació en España. Es un catedrático de Historia del Pensamiento y los Movimientos Políticos y Sociales. En la década del '80 fue profesor visitante en múltiples universidades extranjeras: Oxford y la Sorbona de París. Entre el 2004-2008 se desempeñó como Consejero de Estado.

Esta publicación salió a la luz en un momento particular. España venía de los convulsionados años 2014 y 2015, en que Cataluña había llamado a su población a una elección plebiscitaria en la cual se les preguntaba a sus habitantes, si estaban dispuestos a constituirse en un Estado independiente. Al año siguiente, las elecciones autonómicas, proclamaron como Presidente de la Generalitat a un partido político que enarbolaba las banderas del indepen- dentismo. Por ello es que el contexto general no debe ser soslayado, al momento de lazarnos a la lectura de esta obra.

Muchos han sido los cientistas sociales que desde diversos enfoques han escrito sobre la temática que compete a la obra en cuestión: "nación y nacionalismo". Este libro, si bien no nos aportará, desde el punto de vista investigativo algo nuevo, nos proporcionará una mirada global en lo que refiere a la construcción de las identidades nacionales modernas. Apelando al método comparativo, nos invitará a hacer un recorrido por diversos espacios, permitiéndonos observar, cuáles han sido las similitudes y singularidades en cada caso particular expuesto.

Para poder emprender tan ardua tarea, el autor se servirá de conceptos de otros investigadores reconocidos por sus aportes en estos tópicos, que son de citado obligatorio para cualquier historiador que decida adentrarse en los procesos de creación de este tipo de "comunidades imaginadas". 
Sobre dos ideas fundamentales vertebrará la obra. La primera de ellas, sostendrá que todas las identidades nacionales modernas derivan ineludiblemente de una construcción histórica. Aún, cuando pervivan historiadores más o menos ortodoxos, radicalizados hacia un nacionalismo ineluctable, existe un consenso generalizado que las naciones son una "invención moderna" de carácter funcional que surgieron como respuesta, a aquel cambio estructural, a la transición del Antiguo Régimen Feudal, hacia un Nuevo Orden, regido por la burguesía ilustrada que tenía las pretensiones de instaurar nuevas prácticas diferenciales, que fueran inherentes al contexto dinámico que transcurría.

Ratificará que el concepto nación tiene una carga semántica, debido a su historicidad. Se comenzó a utilizar con la connotación actual hace solo unos siglos atrás, a partir de la experiencia que llevó a cabo Inglaterra. Momento en que empezaron a ser consideradas como identidades colectivas portadoras de una soberanía ejercida sobre un territorio específico, determinado, con fronteras que lo delimitaban.

No quiere decir que el autor no admita que hayan preexistido factores culturales como el lingüístico, la religión, tradiciones, que sumados a la creación de "mitos" o relatos fundacionales, con las claras pretensiones de instaurar un pasado común, hiciesen sentir a sus integrantes como parte de una mancomunidad de intereses; coadyuvando con antelación a una relativa cohesión de estas comunidades.

Por ello es que insistirá en la entelequia de estos tipos de nacionalismos, vistos no solo como una invención interesada sino también funcional a una clase dominante que se erigió por sobre las demás; no pocas veces, apelando al uso desmesurado de la fuerza, para marcar de manera indeleble, los rasgos considerados esenciales que debía poseer aquella "comunidad imaginada” en proceso de construcción.

A su vez, remarcará que la demostración empírica de la invención de las naciones y los nacionalismos debe someter el discurso descriptivo y explicativo, sobre la temática en cuestión a la acumulación rigurosa de datos con el consiguiente análisis exhaustivo de fuentes documentales bibliográficas como así también a la lógica interpretativa que nos brinda la exégesis. Por último, el segundo pilar sobre el que sustenta esta obra es la comparación de casos, lo cual nos permite descubrir las similitudes que revisten entre ellos, como así también establecer las diferencias.

Sostendrá que uno de los escollos muy recurrente, al que se encuentra sometida la historiografía nacionalista tiene que ver con la sumisión de la razón a la emocionalidad, con el consecuente resultado de la imposibilidad de tratar esta problemática desde una perspectiva que imponga la racionalidad ante cualquier clase de sentimiento nacional.

Ante las posturas radicalmente sustancialistas o concepciones esencialistas, que se empeñan de manera obstinada en sostener la naturalidad de los entes nacionales, le opone el imperativo de imprimir una consciencia ciudadana que respondiera a las necesidades del Estado-nación emergente, mediante el poderoso instrumento que le proporcionaron las diferentes instituciones educativas en pos del adoctrinamiento de la "voluntad colectiva".

Otra característica constitutiva insoslayable que comparten todas las naciones modernas es que desde el mismo momento en que comen- 
zaron a constituirse como tales, requirieron establecer una serie de cualidades que las diferenciaran de las otras. En ese sentido, podemos decir que comenzaron a existir en la medida que construyeron su "mismidad" a partir de la diferenciación con una "otredad". En esa misma dirección, es posible plantear que cada Estado-nación, encuentra una reafirmación de aquella identidad, en mayor medida, a partir de lo que niega ser, más que desde la pretendida y utópica homogeneidad, que se despliega desde los discursos historiográficos nacionalistas.

En cada territorio, estuvieron en diputas varios proyectos de Estado-nación, que desde sus respectivas cosmovisiones, emprendieron muchas veces, una lucha encarnizada por imponer hegemónicamente sus ideales. Aunque en repetidas ocasiones son concebidos desde una visión meramente mecanicista y economicista, estos procesos están muy lejos de tener una linealidad, escapan a cualquier concepción teleológica de la historia.

Por ello el autor insistirá en que no pueden ser vistos desde una perspectiva simplificadora, entendiendo que solo existió un plan posible. La nación se sirvió de la exacerbación del nacionalismo para proteger el statu quo y preservar el orden, para de esa manera adoctrinar al ciudadano en una de las premisas fundamentales que consistió en la extirpación de las particularidades. Eliminando así las diferencias y a todos aquellos que conspiraran contra el orden prestablecido, quienes serían identificados inmediatamente, como enemigos internos o externos.

En repetidas ocasiones Álvarez Junco, no escatimará oportunidades en señalar que las identidades nacionales están desprovistas de toda "naturalidad", más allá que la historiografía nacionalista se empecine en ese derrotero explicativo. Por ello es que se propone en cada uno de los ejemplos seleccionados, demostrar que no son entes objetivos, ni mucho menos estables. Al poner la centralidad y el énfasis en que se trata de construcciones políticas y sociales, lo hace con el propósito de desmitificar y derribar los estereotipos preconcebidos, que se encuentran enquistados y anquilosados en las mentalidades del colectivo común de la gente.

Esta "artificialidad" de las identidades nacionales, se encuentra íntimamente relacionada con la "instrumentalización política" por parte de los grupos dominantes que pudieron complementarse y erigirse por sobre otros, sumiéndolos a estos a un papel meramente subalterno. Es que en cada caso podremos ver que la imposición de una identidad, estuvo signada por luchas y pugnas entre diferentes tipos de facciones que no titubearon en utilizar la violencia cuando se vieron amenazados. Exacerbando las características identitarias, propendieron a que cada individuo sintiera un grado de identificación tal que lo llevara a prodigar cierta solidaridad con quienes tuviera o creyera tener cierta afinidad, es decir con aquellos homólogos que se encuentran dentro del marco referencial preestablecido por el Estado-nación.

El autor sostendrá que ante las singularidades de cada territorio, producto de las características geográficas, circunstancias políticas, sociales, culturales, no podemos ver estos procesos como homogéneos. Si bien existió una tendencia a emular lo acontecido en Europa, no quiere decir que existiera una recepción y una reproducción meramente pasivas, de estos modelos, en otras partes del mundo. 
A modo de valoración diremos que la obra cumple con todos los requisitos para ser considerada de divulgación científica. Su prosa simple, amena y llevadera no excluye para nada la rigurosidad que necesita, para sostener cada uno de las afirmaciones, allí vertidas.

Recibido: 25-09-2018 Aceptado: 26-10-2018 Publicado: 07-12-2018

Al tratarse de una apuesta a la exposición de casos, con un planteamiento amplio, se pierden detalles más concretos. Podemos decir que lo que se gana en amplitud desde una concepción global, aplicando una dimensión empírica o escala de observación macro, se pierde en especificidad, al tratar de depurar el relato historiográfico mediante la jerarquización subjetiva y "arbitraria" de los datos. Esto le permite llegar a la conclusión que una serie de casos seleccionados ejemplificarán de manera más eficaz que otros, es decir, que aquellos que finalmente son descartados o excluidos, a los efectos de la obra. Esto se puede ver en el capítulo "Excolonias ibéricas", en el que intenta resumir de manera muy escueta, en unas pocas páginas, procesos que, si bien tuvieron rasgos o características comunes, fueron complejos y con ciertas singularidades, sin lugar a dudas. Hubiera sido oportuno incluir algún caso comparativo, del continente africano, ya que apenas existen algunas vagas referencias al mismo.

Por último, diremos que el libro logra su cometido: desacraliza a la nación, desproveyéndola de la "canonización" que le fue otorgada a través de la historiografía nacionalista, obligándola a descender del cielo de los mitos.

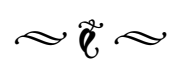

